\title{
4D in Functional Studies of the Fetus
}

\author{
${ }^{1}$ Asim Kurjak, ${ }^{2}$ Panos Antsaklis
}

\begin{abstract}
Assessing fetal neurobehavior has been a great challenge since the first steps of fetal medicine. The introduction of three-dimensional (3D) and four-dimensional (4D) ultrasound technology offered the opportunity to not only examine the fetus anatomically with explicit detail but also to observe the fetus directly and examine its behavior in real time, as one would examine a neonate. The development of the fetal central nervous system (CNS) follows a very structured path and these developmental steps are reflected by the behavior of the fetus in utero for each corresponding week or trimester. Which fetal movements develop during each month and which fetal behavioral patterns are normal or abnormal have been identified. In the same way that a neonatologist can understand by its motoric function if a neonate is premature or not. Similarly, we can now understand which fetal movements-behavioral pattern corresponds to each trimester of pregnancy. Structural and functional impairment of the brain can develop at any time during pregnancy. The structural anomaly of the brain is much easier to detect than functional. Delayed diagnosis of a neurological problem will make the possibility of timely treatment is rather doubtful. It is clear that the assessment of fetal neurological status is of utmost importance, and should be practiced both as a screening test for low- and high-risk pregnancies. The most complete method so far for the assessment of fetal neurobehavior, that relays on real time observation of the fetal behavior with 4D ultrasound and its efficacy has been tested through many multicentric studies is Kurjak's antenatal neurodevelopmental test (KANET). KANET has been introduced in everyday clinical practice and aims to assess the fetal behavior in a similar way that a neonate is assessed postnatally, through 4D ultrasound technology. The KANET has been introduced into systematic training and already ultrasound specialists have been certified to perform this test. Hopefully, application of KANET on larger populations, both high and low risk, will give more knowledge regarding early detection of fetuses at risk for neurological impairment, to allow accurate diagnosis prenatally, and as a consequence prompt intervention that could improve the outcome of some of these neonates postnatally.
\end{abstract}

Keywords: Fetal behavior, Four-dimensional ultrasonography, KANET test, Neurodevelopmental impairment.

${ }^{1}$ Professor, ${ }^{2}$ Lecturer

${ }^{1}$ Department of Obstetrics and Gynecology, Medical School University of Zagreb, Zagreb, Croatia; University Sarajevo School of Science and Technology, Sarajevo, Bosnia and Herzegovina

${ }^{2}$ Fetal and Maternal Medicine, Alexandra Maternity Hospital, Medical School, University of Athens, Athens, Greece

Corresponding Author: Panos Antsaklis, Lecturer, Fetal and Maternal Medicine, Alexandra Maternity Hospital, Medical School, University of Athens, Athens, Greece, e-mail: panosant@gmail.com
How to cite this article: Kurjak A, Antsaklis P. 4D in Functional Studies of the Fetus. Donald School J Ultrasound Obstet Gynecol 2019;13(1):23-33.

Source of support: Nil

Conflict of interest: None

\section{INTRODUCTION}

Assessing fetal neurobehavior has been a great challenge since the first steps of fetal medicine. The introduction of 3D and 4D ultrasound technology offered the opportunity to not only examine the fetus anatomically with explicit detail but also to observe directly the fetus and examine its behavior in real time, as one would examine a neonate. ${ }^{1-3}$ The development of the fetal CNS follows a very structured path and these developmental steps are reflected by the behavior of the fetus in utero for each corresponding week or trimester. Which fetal movements develop during each month and which fetal behavioral patterns are normal or abnormal have been identified. In the same way that a neonatologist can understand by its motoric function if a neonate is premature or not. Similarly, we can now understand which fetal movements-behavioral pattern corresponds to each trimester of pregnancy. ${ }^{4} \mathrm{On}$ the other hand, pregnancy is a long period and there is always a possibility that different factors or incidents can affect this very sensitive and delicate course of fetal brain development. And if this incidence causes an anatomical abnormality to the fetal CNS which can be detected prenatally by ultrasound then a neurological impairment may be suspected, but if an anatomical abnormality is not seen, then a neurological impairment of the fetus will not be suspected and of course will be only diagnosed sometime after birth, and possibly wrongly attributed to intrapartum or even postpartum events.

What is more, a delayed diagnosis of a neurological problem will make the possibility of treating it rather impossible. So what is needed for such cases is a timely diagnosis which will also offer the chance of early treatment-intervention which would aim to a better outcome of these fetuses. It is clear that the assessment of fetal neurological status is of outmost importance, and should be practiced both as a screening test for low-risk pregnancies, but also cases that there is suspicion of neurological impairment prenatally. ${ }^{4-6}$ The most complete method so far for the assessment of fetal neurobehavior, that relays on real-time observation of the fetal behavior with 4D ultrasound and its efficacy 
has been tested through many multicentric studies is Kurjak's antenatal neurodevelopmental test (KANET). KANET has been introduced in everyday clinical practice and aims to assess the fetal behavior in a similar way that a neonate is assessed postnatally, through $4 \mathrm{D}$ ultrasound technology.

\section{Assessment of Fetal Behavior through the Years}

When 2D ultrasound was introduced into clinical practice the fetal movements were observed to draw conclusions regarding the fetal well being and the fetal behavior. ${ }^{7-10}$ Of course, this method is very subjective and inadequate to assess fetal behavior as a whole. The method that offered a complete and real time assessment of the fetus and not just information on isolated limb movements was 4D ultrasonography. ${ }^{11-14}$ $4 \mathrm{D}$ gives the opportunity to examine not only gross fetal movements but also small details such as finger movements, facial expressions, eye blinking, etc. details that are not visible by applying 2D ultrasound. ${ }^{15-17}$
KANET used the advantages of 4D technology and succeeded to assess the fetus in the same way that neonates are assessed neurologically after birth by neonatologists. ${ }^{18-21}$ Apart from the classical fetal movements, KANET through 4D ultrasound introduced all the markers that are used for postnatal neurological assessment according to the Amiel-Tison neurological assessment at term (ATNAT) test. ${ }^{19,22}$ So it also includes the cranial sutures, head circumference and finger movements, detection of neurological thumb (adducted thumb in the clenched feast) and more specifically it includes: isolated head anteflexion, overlapping cranial sutures, head circumference, isolated eye blinking, facial alterations, mouth opening (yawning or mouthing), isolated hand and leg movements and thumb position, gestalt perception of general movements (overall perception of the body and limb movements with their qualitative assessment) (Figs 1 to 3 ). KANET consists of eight parameters, and its aim is to evaluate fetal motoric
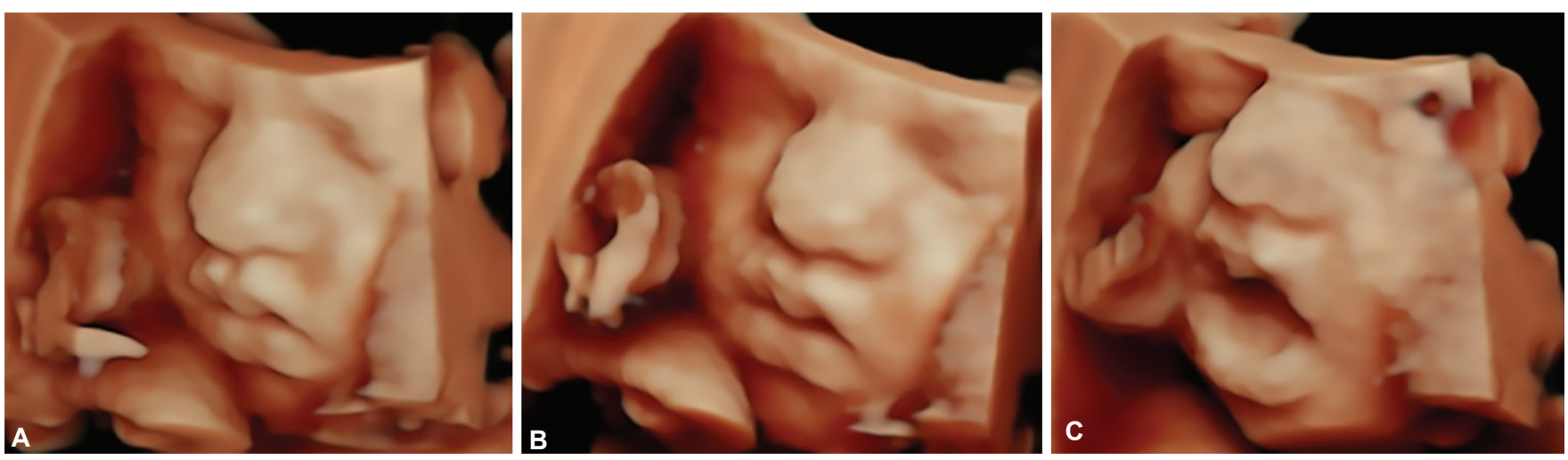

Figs $1 \mathrm{~A}$ to $\mathrm{C}$ : Mouthing as part of the assessment of fetal neurobehavior
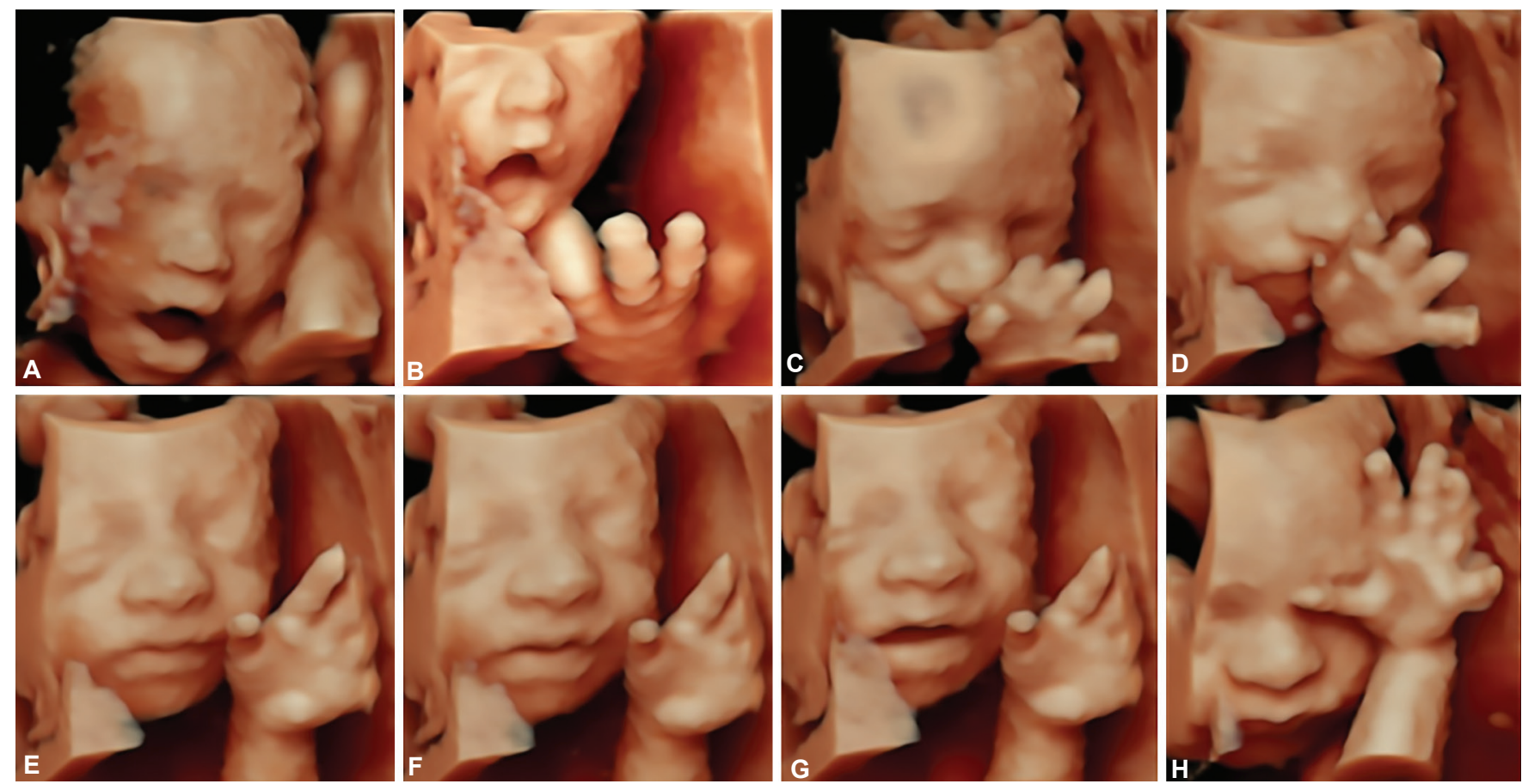

Figs $2 \mathrm{~A}$ to $\mathrm{H}$ : Parameters of KANET test: mouthing, yawning, hand movements 

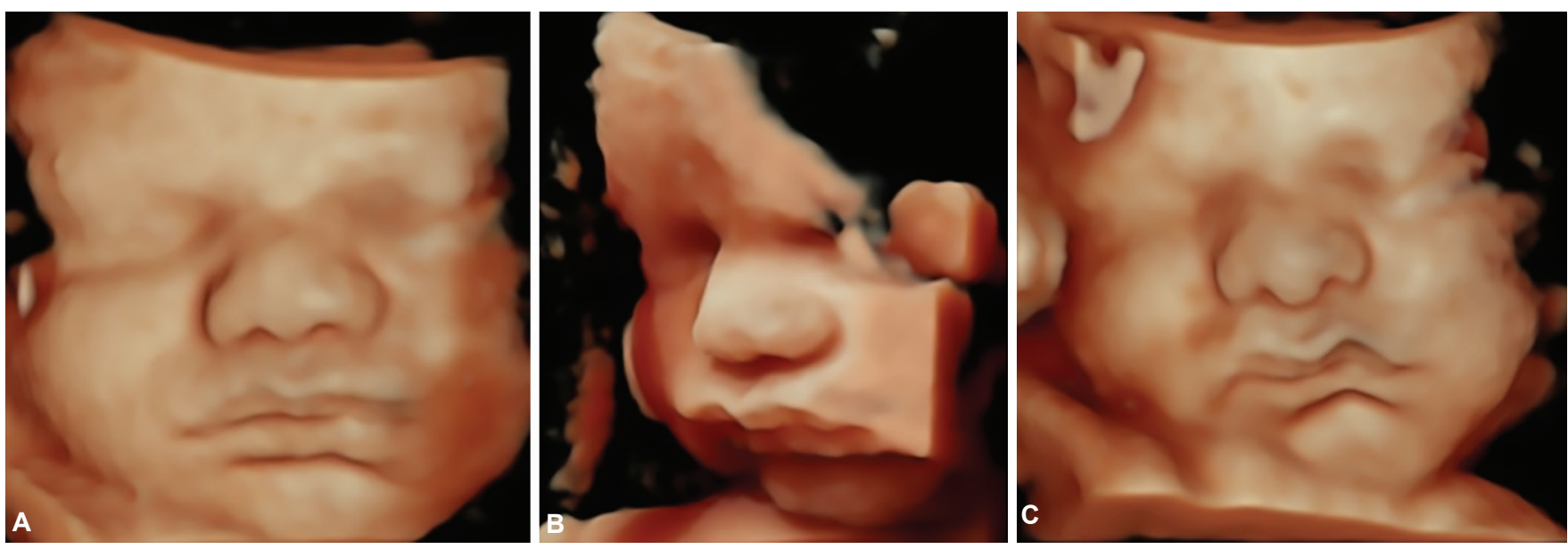

Fig. 3: Facial alterations and grimacing

activity and through that to assess the development and integrity of the fetal nervous system (Table 1).

The maturation of fetal CNS and the transition from fetal to neonatal behavior is a very smooth process, with all movements that are present in postnatal life have been documented with 4D ultrasound in fetal life (with the exception of Moro's reflex, which is not present in fetuses) and that is exactly what KANET has managed to demonstrate and succeed. ${ }^{23}$

KANET is already a standardized method, with good reproducibility as proved by many multicentric studies. Training modules on KANET have been formed, and the training centers show that the learning curve is very reasonable for physicians and medical staff with a good ultrasound background. ${ }^{24}$ Regarding the gestational age at which KANET should be performed, it has been decided that the best period is the 3rd trimester of pregnancy, and particularly after 28 weeks. The duration of KANET should be around 15-20 minutes and should be preferably performed at periods that the fetus is awake. If this is not possible, as it is not always easy to predict when a fetus will be active-awake, and the fetus is quiet for a prolonged period $\mathrm{f}$ time KANET should be repeated within 30 minutes or the following day, at a minimum interval of 14-16 hours.

When KANET is abnormal, or the score is borderline, it is proposed that the test is repeated every two weeks until delivery. Very important features are facial movements and eye blinking- "the face is the mirror of the brain". The overall number of movements must be documented in all cases. ${ }^{22,25}$

Examiners who apply KANET should have proper training, and adequate experience in low and high-risk pregnancies. Interobserver and intraobserver variability have to be documented. The suggestion regarding the ultrasonographic machines used is to have a frame rate of at least 24 volumes/second. The results of KANET are divided into 3 groups:
- Abnormal, when the score is 0-5,

- Borderline for a score from 6 to 13 and finally

- Normal for a score 14-20 (Table 2).

A 2-year follow-up should be available and documented for all fetuses that KANET has been applied, to draw safe conclusions.

KANET has been introduced in training and has been calculated that the number of KANET needed to be performed by an experienced ultrasound specialist to be familiar to assess a fetus with the 4D US in 20 minutes is 80 . The success rate of the test ranges from 91 to $95 \%$ and further study of each parameter reviled a success rate for the assessment of particular signs of $88 \%$ for isolated eye blinking and 100\% for mouth opening and isolated leg movement. KANET has almost $100 \%$ negative predictive value, interobserver variability was satisfactory with the lowest being for the facial expression $(\mathrm{K}=0.68)$ and highest for the finger movements $(K=0.84)$.

\section{Clinical Results of KANET (Table 3)}

The first application of KANET was on growthrestricted fetuses, ${ }^{26}$ where mainly facial expressions and body movements were studied and what was noticed was a decreased behavioral activity in the IUGR fetuses compared to normal growth cases. The study that followed was the first with complete neurologic postnatal assessment for all studied fetuses, and according to the criteria, they used neonates were divided into three groups: normal, mildly or moderately abnormal and abnormal. According to these groups the formation of the first KANET scoring system was decided which was as follows: 14-20 (normal), 5-13 (mildly or moderately abnormal) and 0-5 (abnormal) and based on this scoring system were all the following studies designed. ${ }^{12,27}$

The first study with a large number of high-risk pregnancies identified 32 fetuses at neurological risk: they identified 7 cases with the abnormal score and 25 with a borderline KANET score. There were also 11 cases which 


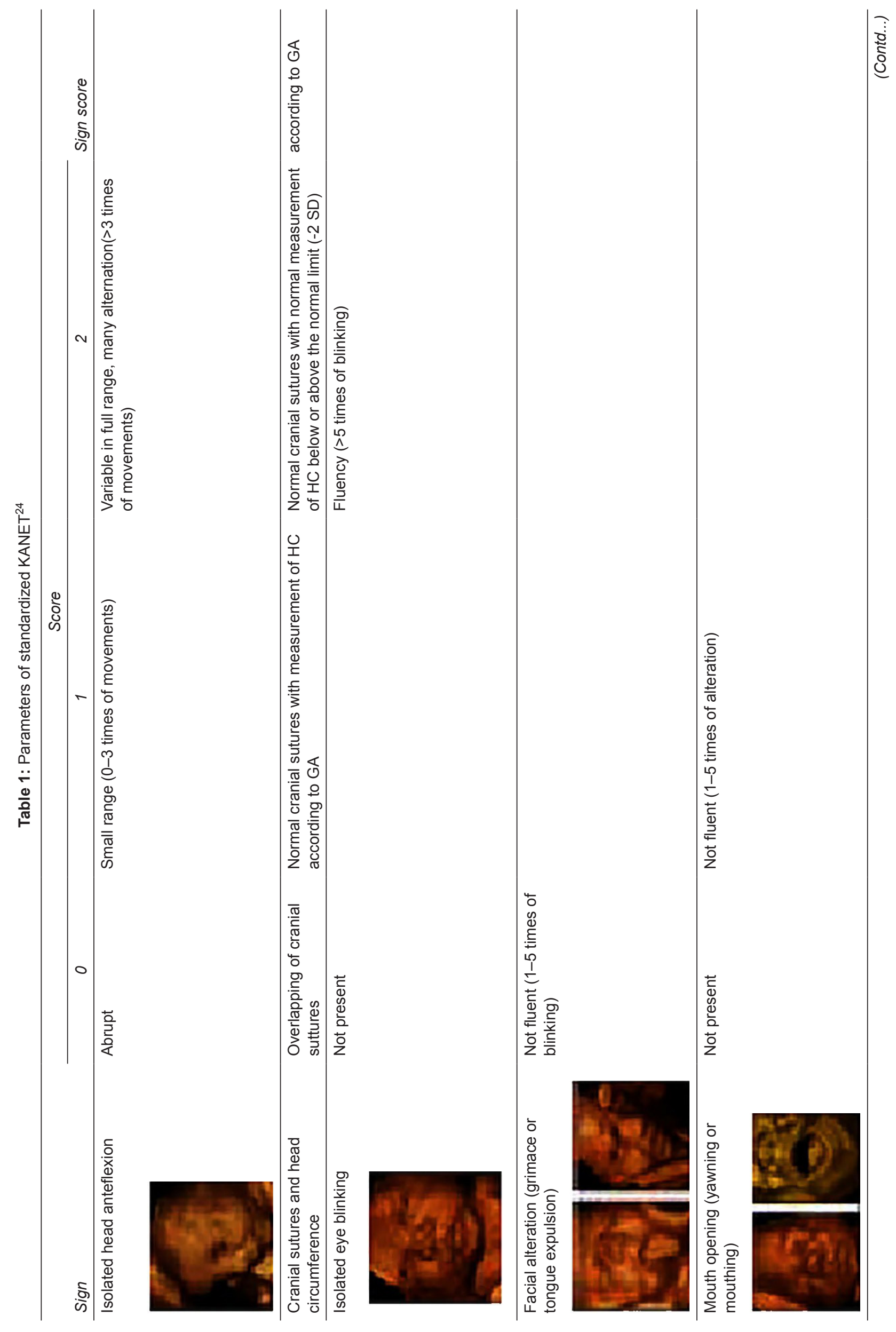




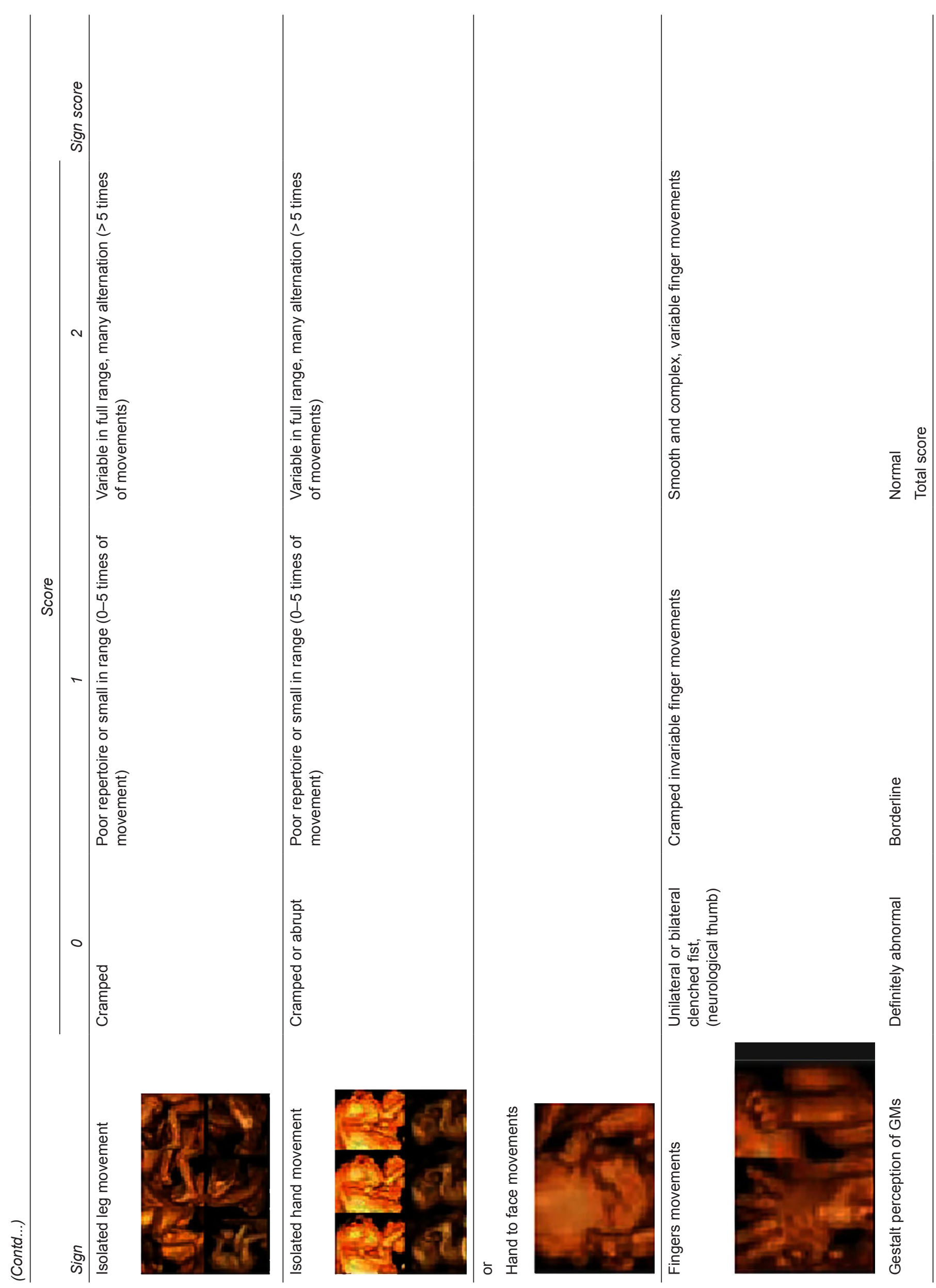

Donald School Journal of Ultrasound in Obstetrics and Gynecology January-March 2019;13(1):23-33 
Table 2: KANET scoring system ${ }^{24}$

\begin{tabular}{ll}
\hline Total Score & Interpretation \\
\hline $0-5$ & Abnormal \\
$6-9$ & Bordeline \\
$10-16$ & Normal \\
\hline
\end{tabular}

either died in utero or had a termination of pregnancy and all of these cases had an abnormal KANET score. The seven remaining neonates with abnormal KANET were followed up postnatally at 10 weeks of neonatal life and 3 had confirmed pathological ATNAT score. These 3 cases included a neonate with arthrogryposis, a neonate with cerebellar vermian complete aplasia and 1 case with a history of cerebral palsy in a previous pregnancy. Out of the parameters that KANET uses, facial expressions appeared to be most pathological-the fetal faces were characterized as "masks" by the authors, due to lack of expressions on 4D ultrasound. The remaining 4 pathological KANET cases had a normal postnatal assessment. These 4 cases, however, had complications of pregnancy: 1 case with ventriculomegaly, 1 case with preeclampsia, 1 case with maternal thrombophilia and 1 case with oligohydramnios. From the 25 cases diagnosed with borderline KANET result, 22 neonates showed a borderline ATNAT score and were followed up, while the 3 remaining cases showed normal ATNAT result. An interesting paper was the one that studied a case of a fetus with prenatally diagnosed acrania. The authors studied the fetal behavior and managed to document how it altered from 20 weeks of gestation onward. It was noticed that as the pregnancy progressed and the control center of motoric activity shifted from the lower to the upper part, KANET score was decreasing respectively, suggesting that neurological damage in later pregnancy is possible. ${ }^{28}$

A study with ${ }^{29} 226$ cases, including different study populations, identified 3 cases with pathological KANET score. All 3 cases had chromosomal abnormalities and all 3 of them postnatally also had an abnormal ATNAT score. Scores from antenatal KANET and postnatal ATNAT were compared between low and high-risk groups, and showed differences between them, for 8 out of the 10 parameters. These included: head anteflexion, eye blinking, facial expressions-grimacing, tongue expulsion, mouth movements such as yawning, jawing, swallowing- isolated hand movements, hand to face movements, fist and finger movements, and general movements.

The comparison of the two tests revealed a correlation between them, proving that the neonatal exam (ATNAT) was a satisfactory confirmation of the prenatal ultrasound examination (KANET), stating that KANET could offer useful information about the neurological status of the fetus and can be applied in clinical practice.
One of the largest studies regarding KANET, ${ }^{30}$ incluing 620 cases, of both low and high-risk populations (100 low risk and 520 high risk cases) showed differences in the scores between the two groups. What was interesting in this study was that most abnormal cases were noted from pregnancies with the previous history of CP (23.8\%) and that most borderline scores were noted in cases with possible chorioamnionitis $(56.4 \%)$. The parameters of KANET that were more notably different between the two groups were: overlapping cranial sutures, head circumference, isolated eye blinking, facial expressions, mouth movements, isolated hand movements, isolated leg movements, hand to face movements, finger movements, and general movements. This study confirmed the relationship of pathological KANET with an increased risk of perinatal mortality and neurological impairment and showed that the results can be confirmed and are reproducible postnatally.

A recent study with a complete follow-up ${ }^{31}$ postnatally up to 3 months of life, with complete postnatal documentation in all cases and showed that a normal KANET score is very reassuring of a good neonatal outcome, confirming the consistency of prenatal and postnatal assessment. Understanding the evolution of fetal movements by 4D ultrasound throughout pregnancy, and how these movements reflect the development and integrity of the fetal nervous system was a great challenge. What was shown was that during the first weeks of pregnancy the development of the frequency and the complexity of fetal movements is more important, while during the second trimester the variation of fetal movements develop, with more detailed movements (facial expressions and eye blinking) appearing at the end of this trimester. Finally, at the end of the third trimester, the number of fetal movements decline as a result of the increase of fetal rest periods, due to fetal cerebral maturation, and this is something that most pregnant women notice near term. ${ }^{12-14}$ A very interesting study which tried to shed some light on the clinical dilemmas caused by the prenatal diagnosis of ventriculomegaly, compared fetuses with ventriculomegaly ${ }^{32}$ with apparently low-risk fetuses (normal CNS appearance on ultrasound examination). A significant difference was noted between the two groups, with the KANET score decreasing as the degree of ventriculomegaly was increasing. For isolated cases of mild or moderate ventriculomegaly, no pathological KANET scores were noted, and postnatal evaluation confirmed the prenatal KANET, offering valuable information for the more complete assessment of these fetuses and better counseling regarding their prognosis.

Abo-Yaqoub et al. ${ }^{33}$ aimed to study how practical is to apply 4D ultrasonography for the assessment of fetal neurobehavior and also how useful it is for the prediction of 


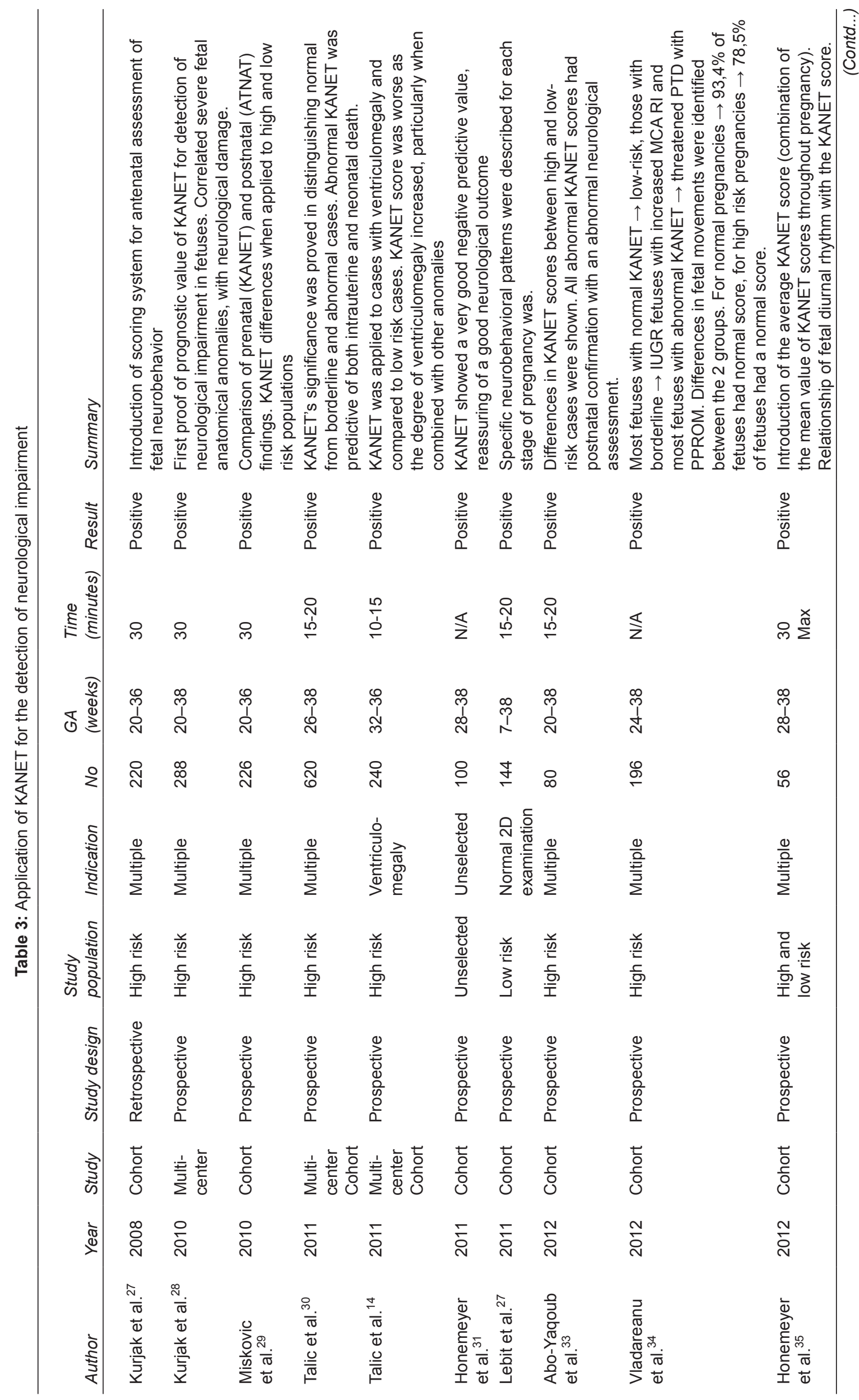




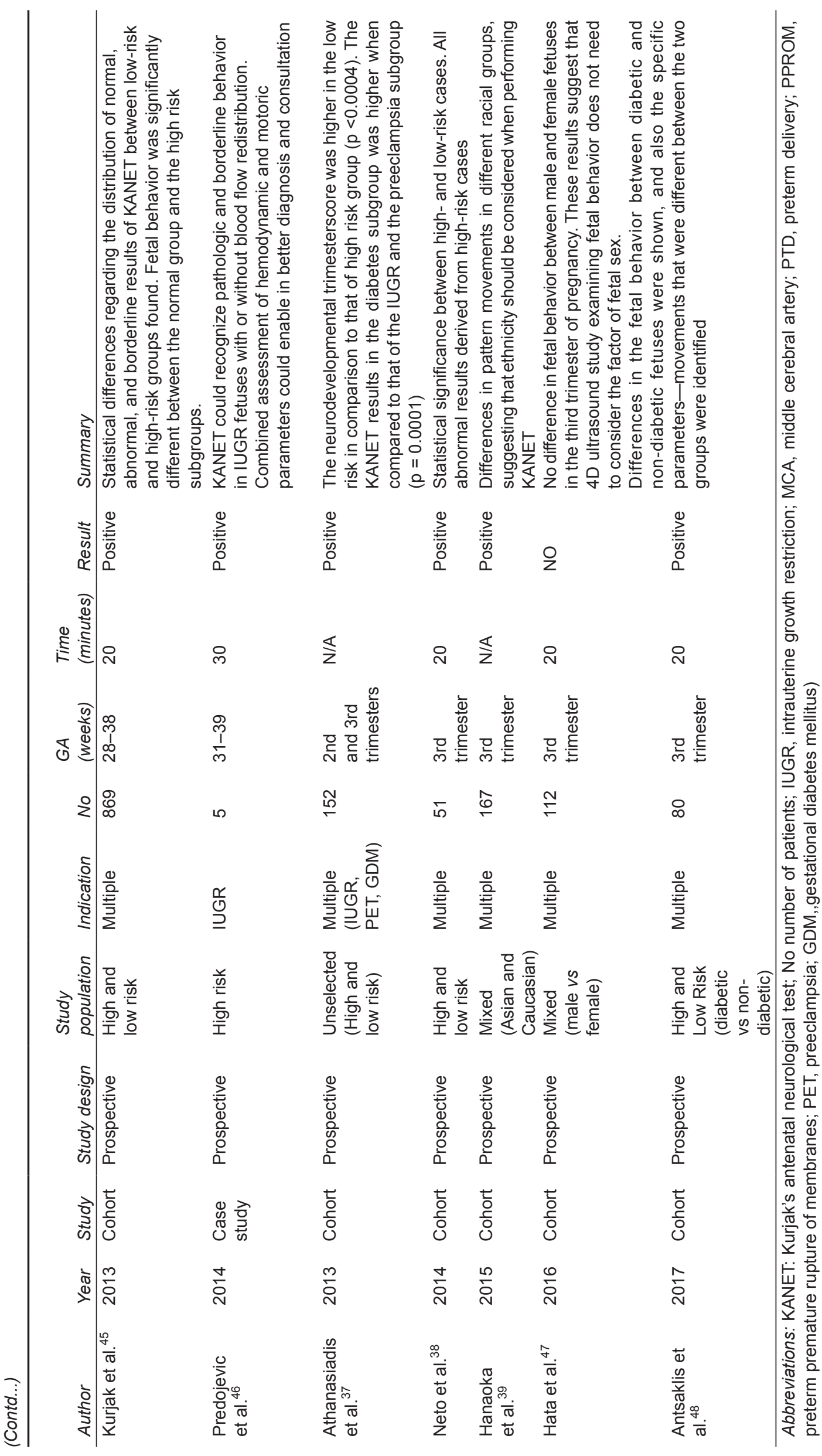


neurological impairment. Their results showed the agreement of prenatal scores with the postnatal assessment. The parameters that were significantly different between the two groups were isolated head anteflexion, isolated eye blinking, facial expressions, mouth movements, isolated hand movements hand-to-face movements, finger movements, and general movements. Regarding isolated leg movements and cranial sutures, the difference was not statistically significant.

Vladareanu et al. ${ }^{34}$ noted that the majority of normal KANET scores derived from low-risk populations that they studied, while the majority of cases with borderline or pathological KANET scores derived from the highrisk groups and in some cases were related to abnormal values of Doppler studies in IUGR fetuses. The authors concluded that KANET can be useful for the detection of neurological impairment which could become obvious during the antenatal or postnatal period.

The average KANET score was introduced for fetuses who had more than one assessments to have a more complete picture of the behavior of these fetuses. The average KANET score derived from the mean calculation of KANET scores for each fetus throughout pregnancy since these fetuses had more than one KANET assessments. What was new from this study was the association of KANET score with fetal diurnal rhythm. For the high-risk group, 89\% of the borderline scores were recorded at times that the mothers characterized them as active periods, compared with $33.3 \%$ respectively in the low-risk pregnancies. ${ }^{35}$

Other studies ${ }^{36,37}$ confirmed the feasibility of neurodevelopment assessment by 4D ultrasound and showed further evidence that KANET test is useful in early identification of fetuses prone to neurological impairment.

What was also important was to compare all parameters of KANET between high and low-risk pregnancies and observe differences in fetal behavior between them. For pathological KANET score 5 out of 8 parameters where significant different: isolated head anteflexion, cranial sutures, and head circumference, isolated hand movement or hand to face movements, isolated leg movement and fingers movements. ${ }^{38}$ Further results showed that only high-risk patients had abnormal scores (8.5\%) while comparing high and low-risk groups it was noticed that $80.6 \%$ of high-risk patients had borderline results while $85.3 \%$ of low-risk patients were normal, both being statistically significant. For abnormal KANET results (score between 0 and 5), some were related to pregnancy complications (preeclampsia, threatened preterm labor and drug abuse) and some were related to fetal condition (trisomies 13, 18 and 21 and intrauterine growth restriction).

When comparing Caucasian to Asian populations to check for ethnic differences, the total KANET score was normal in both populations, but there was a difference noted in total KANET scores between these two populations. When individual KANET parameters were compared, significant differences were observed in four fetal movements (isolated head anteflexion, isolated eye blinking, facial alteration or mouth opening, and isolated leg movement). No significant differences were noted in the four other parameters (cranial suture and head circumference, isolated hand movement or hand to face movements, fingers movements, and gestalt of general movements), showing that ethnicity is a parameter that should be considered when evaluating fetal behavior, especially during the assessment of fetal facial expressions. The authors concluded that although there was a difference in the total KANET score between Asian and Caucasian populations, all the scores in both groups were within normal range proving that ethnical differences in fetal behavior do not affect the total KANET score, but close follow-up should be continued in some borderline cases. $^{39}$

Unpublished data from Greece, from 655 singleton pregnancies, showed that KANET is a method which is feasible in everyday clinical practice, with a success rate of $95 \%$ and a very low negative predictive value. For the cases that KANET could not be completed, the reason was severe oligohydramnios, fibroid uterus (difficult imaging), very increased BMI and a case that due to vasovagal reaction-supine hypotensive syndrome ultrasound examination could not be completed. From the 655 cases, 1712 KANET were performed from only two operators, and the interobserver variability was calculated showing adequate results for all parameters, with the lowest being for facial alterations $(\mathrm{k}$-value $=0.68)$ and the highest for finger movements $(\mathrm{k}-\mathrm{value}=0.84)$. This study was primarily designed to compare the neurological status of pregnancies complicated by diabetes, compared to low-risk pregnancies and it did show that there was a difference between the fetal neurobehavior of these two groups, with the diabetic pregnancies having lower scores. ${ }^{40}$

\section{DISCUSSION}

One of the greatest challenges in perinatal medicine is the assessment of fetal neurobehavior and detection of fetal neurological impairment in utero. KANET is the first method that applied 4D ultrasound for the assessment of the fetus in the same way that a neonate is assessed neurologically after birth by neonatologists and it appears to be a strong diagnostic method for the detection of neurological impairment and for the assessment of fetal neurobehavior, conditions that were inaccessible with the traditional prenatal diagnostic methods used so far. ${ }^{23}$ Studies have proved the validity of this method, ${ }^{13,41,42}$ its applicability in everyday clinical practice, especially for 
high-risk cases, how and by whom it should be performed and what is the value of the result of KANET and how it should be managed. Diagnosis of neurological impairment prenatally is very difficult and usually, all these diagnoses are made postnatally, even months or years after delivery.

What is more neurological conditions, such as cerebral palsy are not adequately understood and falsely attributed to incidents during labor, although it has been proven that the majority of $\mathrm{CP}$ cases originate sometime during in utero life and are not related to intrapartum events. All these things lead to delayed diagnosis of neurological conditions. The later a neurological impairment is diagnosed the less the possibility of an effective intervention. It would be extremely challenging to have a timely diagnosis of such conditions, even during in utero life, to increase the possibility of an effective intervention or even treatment. KANET offers the possibility of prenatal detection of fetuses at risk for neurological problems, offering the possibility of even an in the utero intervention or at least an early postpartum intervention. ${ }^{43}$ The earliest physiotherapy is commenced and intervention programs are applied in neonates that are born prematurely or with neurological problems the better the neurodevelopmental outcome of these neonates, with the cognitive benefits persisting into preschool age. KANET appears to be able to offer this advantage of early identification of these fetuses with neurological problems, so that they could be put under treatment as early as possible, aiming to a better outcome. ${ }^{43,44}$

What is more, the explicitly detailed pictures obtained by the new ultrasound machines but also the advanced techniques of molecular genetics, many times brings us, as ultrasound specialists, across findings (anatomical and chromosomal) of uncertain clinical significance and prognosis, especially regarding the neurological integrity of the fetus. ${ }^{45-47}$ A method like KANET offers a more comprehensive diagnostic approach to such dilemmas and hopefully in the near future with more data, we could form a complete neurosonobehavioral assessment of the fetus and more complete counseling of these couples. ${ }^{48}$

KANET has currently been introduced in everyday clinical practice by many centers for the assessment of fetal neurobehavior of not only high-risk cases, but also low-risk pregnancies. Studies show that the sensitivity and specificity of the test are satisfactory, as are the positive and negative predictive values and the inter- and intraobserver variability of this method. The KANET has been introduced into systematical training and already ultrasound specialists have been certified to perform this examination. Hopefully, application of KANET on larger populations, both high and low risk, will give more knowledge regarding early detection of fetuses at risk for neurological impairment, to allow accurate diagnosis prenatally, and as a consequence prompt intervention that could possibly improve the outcome of some of these neonates.

\section{REFERENCES}

1. Yigiter $A B$, Kavak ZN. Normal standards of fetal behavior assessed by four-dimensional sonography. J Matern Fetal Neonatal Med 2006; 19:707-721.

2. Rees S, Harding R. Brain development during fetal life: influences of the intra-uterine environment. Neurosci Lett 2004; 361:111-114.

3. Joseph R. Fetal brain and cognitive development. Dev Rev 1999;20:81-98.

4. Kurjak A, Carrera JM, Stanojevic M, et al. The role of $4 \mathrm{D}$ sonography in the neurological assessment of early human development. Ultrasound Rev Obstet Gynecol 2004; 4:148-159.

5. Stanojevic M, Zaputovic S, Bosnjak AP. Continuity between fetal and neonatal neurobehavior. Semin Fetal Neonatal Med 2012; 17:324-329.

6. Haak P, Lenski M, Hidecker MJ, et al. Cerebral palsy and aging. Dev Med Child Neurol 2009;51:16-23.

7. Precht HF. Qualitative changes of spontaneous movements in fetus and preterm infant are a marker of neurological dysfunction. Early Hum Dev 1990; 23:151-158.

8. de Vries JI, Visser GH, Prechtl HF. The emergence of fetal behaviour. II. Quantitative aspects. Early Hum Dev 1985; 12:99-120.

9. de Vries JI, Visser GH, Prechtl HF. The emergence of fetal behaviour. III. Individual differences and consistencies. Early Hum Dev 1988; 16:85-103.

10. de Vries JI, Visser GH, Prechtl HF. The emergence of fetal behaviour. I. Qualitative aspects. Early Hum Dev 1982;7: 301-322.

11. Kurjak A, Luetic AT. Fetal neurobehavior assessed by threedimensional/four dimentional sonography. ZdravVestn 2010; 79:790-799.

12. Salihagic-Kadic A, Medic M, Kurjak A, et al. 4 D sonography in the assessment of fetal functional neurodevelopment and behaviouralpaterns. Ultrasound Rev Obstet Gynecol 2005; 5:1-15.

13. Kurjak A, Pooh R, Tikvica A, et al. Assesment of fetal neurobehavior by 3D/4D ultrasound. Fetal Neurology 2009:222-250.

14. Lebit DF, Vladareanu PD. The role of $4 \mathrm{D}$ ultrasound in the assessment of fetal behaviour. Maedica (Buchar) 2011; 6:120-127.

15. Merz E, Abramowicz JS. 3D/4D ultrasound in prenatal diagnosis: Is it time for routine use? Clin Obstet Gynecol 2012; 55:336-351.

16. Kurjak A, Vecek N, Hafner T, Bozek T, Funduk-Kurjak B, Ujevic B. Prenatal diagnosis: what does four-dimensional ultrasound add? J Perinat Med 2002; 30:57-62.

17. Kurjak A, Vecek N, Kupesic S, et al. Four-dimensional ultrasound: how much does it improve perinatal practice? In: Carrera JM, Chervenak FA, Kurjak A, editos. Controversies in perinatal medicine, studies on the fetus as a patient. Parthenon Publishing: New York; 2003 p. 222.

18. Kurjak A, Miskovic B, Stanojevic M, et al. New scoring system for fetal neurobehavior assessed by three- and fourdimensional sonography. J Perinat Med 2008; 36:73-81. 
19. Gosselin J, Gahagan S, Amiel-Tison C. The Amiel-Tison Neurological Assessment at Term: conceptual and methodological continuity in the course of follow-up. Ment Retard Dev Disabil Res Rev 2005; 11:34-51.

20. Amiel-Tison C, Gosselin J, Kurjak A. Neurosonography in the second half of fetal life: a neonatologist's point of view. J Perinat Med 2006; 34:437-446.

21. Tomasovic S, Predojevic M. 4D Ultrasound - Medical Devices for Recent Advances on the Etiology of Cerebral Palsy. Acta Inform Med 2011; 19:228-234.

22. Kurjak A, Stanojevic M, Andonotopo W, et al. Fetal behavior assessed in all three trimesters of normal pregnancy by fourdimensional ultrasonography. Croat Med J 2005; 46:772-780.

23. Stanojevic M, Kurjak A, Salihagic-Kadic A, et al. Neurobehavioral continuity from fetus to neonate. J Perinat Med 2011; 39:171-177.

24. Stanojevic M, Talic A, Miskovic B, et al. An attempt to standardize Kurjak's antenatal neurodevelopmental test: Osaka Consensus Statement.Donald School J Ultrasound ObstetGynecol 2011; 5:317-329.

25. Kurjak A, Andonotopo W, Hafner T, et al. Normal standards for fetal neurobehavioral developments--longitudinal quantification by four-dimensional sonography. J Perinat Med 2006; 34:56-65.

26. Andonotopo W, Kurjak A. The assessment of fetal behavior of growth restricted fetuses by $4 \mathrm{D}$ sonography. J Perinat Med 2006; 34:471-478.

27. Kurjak A, Carrera J, Medic M, et al. The antenatal development of fetal behavioral patterns assessed by four-dimensional sonography. J Matern Fetal Neonatal Med 2005; 17:401-416.

28. Kurjak A, Abo-Yaqoub S, Stanojevic M, et al. The potential of $4 \mathrm{D}$ sonography in the assessment of fetal neurobehaviormulticentric study in high-risk pregnancies. J Perinat Med 2010; 38:77-82.

29. Miskovic B, Vasilj O, Stanojevic M, et al. The comparison of fetal behavior in high risk and normal pregnancies assessed by four dimensional ultrasound. J Matern Fetal Neonatal Med 2010; 23:1461-1467.

30. Talic A, Kurjak A, Ahmed B, et al. The potential of $4 \mathrm{D}$ sonography in the assessment of fetal behavior in high-risk pregnancies. J Matern Fetal Neonatal Med 2011; 24:948-954.

31. Honemeyer U, Kurjak A. The use of KANET test to assess fetal CNS function.First 100 cases. 10th World Congress of Perinatal Medicine 8-11 November 2011. Uruguay. Poster presentation P209.

32. Talic A, Kurjak A, Stanojevic M, et al. The assessment of fetal brain function in fetuses with ventrikulomegaly: the role of the KANET test. J Matern Fetal Neonatal Med 2012; 25:1267-1272.

33. Abo-Yaqoub S, Kurjak A, Mohammed AB, et al. The role of 4-D ultrasonography in prenatal assessment of fetal neurobehaviour and prediction of neurological outcome. J Matern Fetal Neonatal Med 2012;25:231-236.

34. Vladareanu R, Lebit D, Constantinescu S. Ultrasound assessment of fetal neurobehaviour in high-risk pregnancies. Donald School J Ultrasound ObstetGynecol; 2012;6:132-147.

35. Honemeyer $\mathrm{U}$, Talic A, Therwat A, et al. The clinical value of KANET in studying fetal neurobehavior in normal and at-risk pregnancies. J Perinat Med 2013; 41:187-197.

36. Kurjak A, Talic A, Honemeyer U, et al. Comparison between antenatal neurodevelopmental test and fetal Doppler in the assessment of fetal well being. J Perinat Med 2013; 41:107-114.

37. Athanasiadis AP, Mikos T, Tambakoudis GP, et al. Neurodevelopmental fetal assessment using KANET scoring system in low and high risk pregnancies. J Matern Fetal Neonatal Med 2013; 26:363-368.

38. Neto RM. KANET in Brazil: First Experience. Donald School J Ultrasound ObstetGynecol 2015;9(1):1-5.

39. Hanaoka U, Hata T, Kananishi K, et al. Does ethnicity have an effect on fetal behavior? A comparison of Asian and Caucasian populations. Journal of Perinatal Med. 2016 Mar;44(2):217-221

40. Kurjak A, Stanojevic M, Andonotopo W, et al. Behavioral pattern continuity from prenatal to postnatal life--a study by four-dimensional (4D) ultrasonography. J Perinat Med 2004; 32:346-353.

41. Andonotopo W, Kurjak A, Kosuta MI. Behavior of an anencephalic fetus studied by 4D sonography. J Matern Fetal Neonatal Med 2005; 17:165-168.

42. Kurjak A, Predojevic M, Salihagic-Kadic A. Fetal brain function: lessons learned and future challenges of $4 \mathrm{D}$ sonography. Donald School J Ultrasound ObstetGynecol 2010; 2:85-92.

43. Stanojevic M, Antsaklis P, Salihadic-Kadic A, et al. Is Kurjak Antenatal Neurodevelopmental TestReady for Routine Clinical Application? Bucharest Consensus Statement. DSJUOG July-September 2015(9);3:260-265

44. Spencer-Smith MM, Spittle AJ, Doyle LW, et al. Long-term benefits of homebased preventive care for preterm infants: a randomized trial. Pediatr 2012;130(6):1094-1101.

45. Kurjak A, Talic A, Honemeyer U, et al. Comparison between antenatal neurodevelopmental test and fetal Doppler in the assessment of fetal well being. J Perinat Med 2013; 41:107-114.

46. Predojević M, Talić A, Stanojević M, et al. Assessment of motoric and hemodynamic parameters in growth restricted fetuses-case study. J Matern Fetal Neonatal Med 2014; 27:247-251.

47. Hata T, Hanaoka U, Mostafa AboEllail MA, et al. Is there a sex difference in fetal behavior? A comparison of the KANET test between male and female fetuses. J Perinat Med. 2016 Jul 1;44(5):585-588.

48. Antsaklis P, Porovic S, Daskalakis G, et al. 4D assessment of fetal brainfunction in diabetic patients. J Perinat Med. 2017 Aug 28;45(6):711-715. 